\title{
Leaving Home? Global Education Strategies
}

\author{
Mary Ann Tétreault \\ Department of Political Science, Trinity University, San Antonio, Texas, USA \\ Email: moontyger@earthlink.net
}

Received 13 January 2015; accepted 2 February 2015; published 4 February 2015

Copyright (C) 2015 by author and Scientific Research Publishing Inc.

This work is licensed under the Creative Commons Attribution International License (CC BY).

http://creativecommons.org/licenses/by/4.0/

(c) (i) 0 pen Access

\begin{abstract}
College in much of the West is the formal site of higher education but what is expected from college is education more broadly conceived. The university is a place where students come to learn but it also is a collection of spaces where informal learning builds their capacities to create and perform on a larger stage than family and neighborhood. The public sphere constituted by the university is sheltered, but students are still exposed to individuals from different backgrounds and encouraged to expand their horizons to embrace concerns that lie outside the interests and competence of their families and neighborhoods. The adults and peers who surround them make demands that each student must either accommodate or resist. How to make these choices is an important element of both "global education" and the transition to adulthood. Some of this informal learning is accomplished through leaving home to join a university community. Here I examine the structures and practices that influence informal student learning where the relative impact of the home and the university differ. I also look at three study-abroad programs, arguing that the spaces and places of education in a foreign country remain influenced by the cultural values of home and home institutions. My purpose is to evaluate the extent to which these universities and programs prepare graduates for life in a globalized world, and to determine some of the reasons lying behind the differences.
\end{abstract}

\section{Keywords}

Global Education, Informal Learning, Study Abroad, Space and Place, Protected Spaces, Resilience, Diversity

\section{Introduction}

College in much of the West may be the formal site of higher education but what is expected from a college is education broadly conceived. The university is a place where students come to learn but it also is a collection of variously protected spaces (Tétreault, 1993) within which they can discover their capacities to create and perform on a larger stage than family and neighborhood. They enter as adolescents, bursting with potential; they 
depart three or four years later, as young adults. If their time has been well-spent, they leave with the tools and nascent networks they need to embark on their life journeys. Many of the tools are skills transferred explicitly as part of their "education" such as the ability to write clearly, do mathematics, master a foreign language, organize and conduct investigations, speak before an audience, use technology, perform as artists. Other tools also are skills but are learned by experience rather than taught explicitly in the classroom. Examples are how to adapt to unexpected circumstances, how to choose friends and allies, how to identify and solve problems, when to abandon what "everybody knows" for knowledge that contradicts accepted wisdom, how to identify, build, and flourish in communities - the several networks that will sustain them professionally and personally throughout their lives (Fischer, 2013; Sotomayor, 2013).

The university is a part of the public sphere, but it is not fully public. There are standards for admission and retention that result in a substantially self-selected population with many shared interests, expectations, and goals. Even so, students are exposed to individuals they have never met before, some from different cultural backgrounds, varied life experiences, and different world views. Neither the adults nor the peers who surround them are responsible for them or as interested in what they do as their families and friends are. At the same time, these individuals make demands that each student must adjust to whether or not s/he decides to accommodate or resist those demands. How to make these choices and act on them are key elements of the transition to adulthood, and necessary skills for success in professional life.

For most US students, much of this informal learning is accomplished through living in the university community. Leaving home for college is a rite of passage, a transition from childhood to a more independent style of life. The familiar world of parents, siblings, and childhood friends is left behind. Students are responsible for organizing their own time, space, and activities. They try out new ideas, new techniques, new looks. Even though they may be able to go home for holidays and perhaps an occasional weekend, in between home visits they have to make places for themselves: organize their own physical and emotional sustenance and fight their own battles. They must deal with the people they disagree with respectfully, as though they were rational creatures just like themselves. In a fundamental sense, failures in adjusting to these tasks are as or more critical to growth and development than successes, especially if failure happens early, while students can see or be helped to see their mistakes, and modify their behavior so that they can avoid similar errors in the future.

Among the two most important of these informal lessons are skills in networking, and an ability to adjust to change. A student who develops relationships with new colleagues adds to her/his potential professional "contacts" and acquires a handful of adult friends who, ideally, last well beyond graduation. Contacts share interests and common experiences. Their familiarity is based on encounters that reveal each other's skills, competence, and reliability. Close friends bond by sharing common experiences beyond the university. These relationships of choice expand and deepen over time. Shared interests develop into respect and affection which, in turn, enlarge the friends' common experiences and life spaces. Robert Frost wrote that "home is where, when you have to go there, they have to take you in" (Frost, 1914). Close friends expand each other's home spaces and thereby the strength and security of each other's lives.

Resilience is the capacity to understand and operate in novel situations. Learning to adjust to new settings and new people in a university's semi-protected environment allows room for mistakes where errors rarely are fatal. Ideally, failure is a place to start again with clearer ideas about what eventual success requires. The resilient student learns how to evaluate people and situations beyond prior experience, and to look for opportunities in novelty rather than seeing it as an obstacle. Resilient individuals also are able to refine their capacity to recognize different measures of achievement and success, thereby enlarging their own action repertoires.

In this paper, I argue that informal elements of higher education are products of the spaces and places where they occur: the home and the university. I look at three cases to compare their students' experiences of space and place: the American University of Kuwait (AUK), where there are no boarding students; Trinity University in San Antonio, Texas, which, like AUK also is a private liberal arts institution but one where most students live on-campus; and Old Dominion University (ODU), a large public university located in Norfolk, Virginia, where most students commute to school as AUK students do. Both US universities draw a significant proportion of their student bodies from the local area (i.e., Texas or Virginia) just as AUK does.

US colleges and universities devote some effort to providing opportunities for students to engage in informal learning but much of it is accomplished simply by experiencing the campus as a defined place away from home. Trinity, for example, requires all students to live on campus during their first three years no matter where their families reside. The educational space at all three institutions is enlarged through field trips and community 
projects that offer glimpses into unfamiliar work and living environments. Internships introduce students to the demands of the workplace, and sometimes serve as stepping-stones to full-time positions after graduation.

Commuter and residential institutions both feature study-abroad programs. Kuwaiti students who study abroad usually go for more than a year, not only to see the world but also for professional training and to acquire foreign-language proficiency. One concern is that students who receive a large proportion of their higher education abroad may become alienated from their home cultures (Ericksen, 2013; Hausheer \& Toops, 2012). US students, who generally spend only a semester or a full year at a foreign university, study abroad for related reasons. Limiting the amount of time they can study abroad is a means to keep them connected to the home university community (Ericksen, 2013). Another strategy for maintaining connections to home is to send students abroad as a group, along with home-country faculty, in so-called island programs (see below).

Along with mastering their subjects, study-abroad students encounter individuals whose politics, business models, or social practices can be very different from their own. In adapting to situations where their basic assumptions are not always shared and may be sharply challenged, they acquire critical distance from their home countries (Zylstra, 2013). In addition to developing human relations and communication skills, they enjoy a space within which to consider and choose from among the unfamiliar aspects of their lives abroad those values, models, and practices that they hope to apply in their own lives when they return (e.g. BBC, 2012; IES, n.d.).

To illustrate some of the contributions of study-abroad to informal learning, I end this essay with a brief look at three programs, two American and one from the Gulf. The US programs are run by the Colorado School of Mines, a highly competitive university located in Golden, Colorado, which specializes in engineering; and Central College in Pella, Iowa, a small, private, religiously affiliated liberal arts college nationally known for its study-abroad program. To Mines and Central, internships and study-abroad are key education strategies explicitly designed to enlarge the personal and professional experiences of members of relatively homogeneous student bodies. I also discuss a preliminary evaluation of the effectiveness of a new Saudi study-abroad initiative, the King 'Abdullah Scholarship Program (Hausheer \& Toops, 2012). This example of a large program that sends students from the Gulf to the United States illustrates some of the limitations of relying on space over place as the primary location for productive indirect learning.

\section{The Value of Indirect Learning}

\subsection{Diversity and Community}

The diversity of a university community contributes to education by providing occasions of direct sharing of ideas, assumptions, and experiences where students can compare anything from family dynamics to religious beliefs, food preferences, or economic and social status with people who are, at the time of sharing, their peers. The simultaneous experience of common and divergent identities and reactions to particular situations and events enables students to evaluate the relative importance of elements such as identity, belief systems, and background as compared to qualities such as dependability, competence, and character. For traditional undergraduates, the university is often the most important place where this transformation takes place.

Community contributes to the moral standing of difference, and thereby to the strategies students develop to understand and work with it. Despite organizational hierarchies of faculty and administration, the university community is horizontal. Significant autonomy rests with individuals who have to earn their places in multiple settings. Although horizontal social aggregates such as departments, majors, and classes share interests, they are composed of people from different families, neighborhoods, religions, social classes, and countries. Students working together in these settings operate on the basis of their commonalities as students in the same course or institution. Difference is thereby normalized. Partners and colleagues are selected for competence, reliability, and congeniality. Similarities across differences also are normalized in that students see others sharing their values and goals-laughing at the same jokes—despite social or class differences.

Networks and friendships are initiated in these horizontal settings. Relationships rest on trust based on performance rather than on identity or affiliation. The social skills that lead to success in university communities are the same ones adults call upon when they are working with counterparts from different countries and cultures (including corporate cultures), where part of their job is to find reliable partners in spite of differences. In novel situations, where customary signals indicating reliability and competence are missing or unintelligible, the resilient adult is one who has learned how to look for signals that operate in those milieux (Godel-Gengenbach, 2013). 


\subsection{Adjusting to Unfamiliar Standards}

Strategies for self-preservation and success are acquired from infancy, and help children attract the attention and support they need from families and friends (Hrdy, 2011; Sulloway, 1996). These strategies can be applied in other settings, but resilience depends on being able to adjust or devise new strategies in settings where the underlying assumptions or conditions that gave rise to the original ones no longer operate. Frank Sulloway (1996) argues that individuals from the same family occupy distinct niches that favor particular strategies for success, but these strategies might not be suitable in different places or under different circumstances. Learning to identify and apply a strategy that fits an unfamiliar situation requires experience and practice. Living with strangers, whether as roommates in a dormitory or apartment, or as a foreign student studying abroad, is a source of both.

\section{Space and Place at Three Universities}

Space and place are fluid concepts that overlap conceptually, leading to contestation within and across disciplines. Space is generally viewed as a geographic location, but it also refers to how people perceive those locations and what goes on within them (e.g. Holt-Jensen, 1999). In a somewhat overlapping definition, "place is a portion of geographical space... [s]ometimes defined as 'territories of meaning'” (Holt-Jensen, 1999: 224). Universities occupy physical spaces within which there are many places, but we also can think of such places as extending into spaces outside the geography of the university. So, for example, AUK and Trinity occupy spaces partly or entirely defined by walls and gates. The spaces are private even though parts of Trinity, including offices and fraternity houses, spill into the surrounding residential neighborhood composed of the private spaces of homeowners. Spaces in the vicinity of a university where students and faculty abound may be thought of taking on some of its character, such as the Trinity or ODU "neighborhood". Place also spills into spaces beyond the campus that are associated with a university's identity.

In contrast to AUK and Trinity, ODU does not have an enclosed campus, although many facilities are concentrated along a main thoroughfare. Unbounded, they extend into nearby commercial, residential, and industrial areas, and into other towns and cities. ODU has a geographic center that includes a cluster of colleges, the library, and unique facilities like the orchid conservatory. There is some "residential" housing owned by the university, but most students live at home or in apartments in privately owned buildings. ODU's extensive space includes branch facilities throughout the Hampton Roads area, and a significant distance-learning component, some of which is aimed at highly mobile military service members. Although the spaces of AUK and Trinity often coincide with specific locations, ODU's spaces are more consistent with notions of place, such as spaces in public buildings or on military bases that also are used by others.

The importance of space and place as ingredients of higher education lies in how they contribute to the students' passage to adulthood, particularly the development of autonomy and self-sufficiency enabling individuals to make choices and take responsibility for them, not only in their private lives but also as citizens, workers, and leaders. The content of education provides knowledge and practical skills. The indirect education students receive from the university environment itself is more diffuse.

The common experiences of students create bonds between them that may develop into elements of adult friendship and professional networks. Students develop relationships of trust with peers and professors whom they can call and rely upon even after graduation. They learn to recognize desirable qualities they can spot later in potential supervisors, subordinates_-and spouses - who may or may not share the same identifying characteristics as members of their childhood communities. Students build upon and enlarge their criteria for evaluating values and behaviors worthy of emulation — or avoidance. The university as a place allows students to put "good" behaviors into practice because there they have a minimal past life to tether them to things they wish to change about themselves. It is not that university students reject their past, their families, or their friends but rather that they enlarge the pool of individuals and types of models they wish to incorporate in their own lives (BBC, 2012; Sotomayor, 2013). Thus, the university is a place where students can develop a wide range of talents, identify their personal strengths and weaknesses, and try out strategies to win new friends and appeal to people whose cooperation or opposition can affect their future success in life.

\subsection{Space and Place at AUK}

The American University of Kuwait is located in Salmiya, a part of Kuwait where many foreigners live. It occupies the tree-shaded campus of a former kindergarten and is a secure facility with gates and guards able to ob- 
serve and regulate who comes in or out. AUK is near the seaside and not too far from a large mall with many restaurants and shops that was quite fashionable when it first opened but has since been superseded by newer, bigger, and fancier shopping centers. On-campus, students can congregate in a restaurant, cafés, in building lobbies which have few places to sit down, and on benches under the eaves of buildings where they can sit in the shade and chat with friends-and smoke. Students generally drive in or are dropped off for classes and many leave when their last class is over. There are a number of student organizations and student groups engaged in projects that meet in empty classrooms or in public rooms. A few offices, like student services, have space with comfortable seating where students can meet although how it can be used is limited by the lack of privacy and the fact that business is conducted there. Overall, however, there are few places on campus where students can congregate comfortably in groups or just hang out with no specific purpose in mind other than socializing.

AUK's self-contained campus suggests its suitability as a place for social interaction and the development of strong community bonds among students and faculty, but limitations on spaces impair its ability to do this. In contrast with private institutions of a similar size in the United States, the model AUK aspires to follow, it is not a home away from home. Envisioned initially as a technical school that would follow an American curriculum in an American-style campus environment, other than by employing foreign faculty and emphasizing English-language skills, it offers little in the way of an American-style "college" experience on a day-to-day basis. Rather, it appears to take an instrumental view of its role as an institution that supplies instruction, and devotes little attention to providing places for students and faculty to socialize. In this sense, it more closely resembles US community colleges than four-year, residential institutions. Another drawback to cross-group networking is that many AUK students are "recruited" by the kin and friendship networks of their families which encourages the formation of cliques and reinforces the relative contribution of family-and-friends to the intellectual and professional socialization of AUK graduates.

The American-ness of AUK is seen by the university administration as centered on its unique-for-Kuwait liberal arts emphasis. Liberal arts incorporates informal learning and is purposely designed to broaden students' exposure to general knowledge as well as the arts. AUK is licensed to offer up to seven degrees in engineering, five in business administration, and five in social sciences and humanities. Then-AUK dean Nizar Hamzeh noted that

A shift toward liberal arts education occurred immediately. As of 2004 (when AUK admitted its first students), liberal arts became the main mission. Emphasis was placed on humanities and social sciences. Business is taught in the context of liberal arts—even engineering. Branching curriculum from 120 credits-45 general education, add 18 credits of free electives-general education and liberal arts-the remaining is less than 60 , which goes to the major. In computer engineering we were forced to increase degree requirements to [131] credits... So we became, as of 2004, the main liberal arts institution of Kuwait. It makes AUK distinctive (Hamzeh, 2010).

Yet although the liberal arts emphasis is formally embedded in the curriculum, it is not so much so that students are ensured a broadly oriented education. For example, they can take all their "liberal arts classes" in social sciences and graduate without even one course in history or the arts. In spite of such structural deficiencies (some due to policies of the Ministry of Education—see Tétreault, 2011), AUK strives to provide places where students able and willing to seize the opportunities offered can enrich their university experiences through participation in on-campus projects like fairs, debates, theatrical performances, and public lectures.

There are opportunities for students to travel to foreign countries for a wide range of academic reasons. They attend and make presentations at conventions, and travel in groups to cities in Europe, Asia, and the Americas to see the geography, architecture, art, and economies of places very different from Kuwait. Kuwait is a partner institution of Dartmouth College in New Hampshire, and regularly sends interns for summer work in Hanover, one of several programs that link Dartmouth and AUK. In 2012, five interns worked at Dartmouth in locations as varied as an art museum and a media-production group. One worked in the center for world languages, tutoring Dartmouth students in spoken Arabic. Such internships are especially effective in demonstrating operations - how such places work — in addition to exposing students to a new country and people (Pearson, 2012).

AUK employs Kuwaiti as well as foreign faculty, virtually all of whom received their advanced degrees abroad. There is no tenure system at AUK and little in the way of grievance procedures. Even so, there is some de facto stability in the composition of AUK faculty and staff despite the lack of institutional brakes to moderate turnover or protect faculty members from harassment in or outside of the university. The rising number of pri- 
vate universities in Kuwait and elsewhere in the region offer employment alternatives, but these alternatives support little more than a system biased against the retention of controversial employees likely to be among the most demanding and provocative teachers. Even so, many AUK professors devote considerable time and energy to working with interested students on projects as varied as anthropologist Marjorie Kelly's "Kuwait at Fifty" video celebrating the country's fiftieth anniversary as an independent nation-state, and Amir Zeid's mentoring of AUK computer science students who have competed in the Microsoft Imagine Cup since 2010. The Imagine Cup provides, in addition to mentoring and individual instruction, another overseas opportunity for winners to travel. After winning in its region, AUK sent teams to compete in world finals in Poland, the United States, and Australia (N.A., 2012a and b).

\subsection{Space and Place at Trinity}

The Trinity campus also is self-contained but much larger than AUK's, with dormitories, gymnasia, a large student center, and buildings with places for informal student interactions, such as a coffee shop in the library and lobbies in several academic buildings with comfortable chairs, tables, and ready access to computer labs, as well as to faculty offices and classrooms. Most campus buildings are constructed from "Trinity brick" whose distinctive size and color confer a visual unity on the campus. The dormitories and dining hall house and feed virtually all freshmen, sophomores, and juniors, along with some seniors; fraternity and sorority houses are where subcommunities thrive; intercollegiate sports attract student participants and fans from across the campus; and outdoor spaces with and without formal seating arrangements are places where students regularly congregate and where classes are sometimes held. One is a fountain! Student activities take place all day long and well into the night. Multiple student organizations with various missions attract members who share religious or ethnic affiliations, political interests, academic ambitions, and/or social goals. Many have faculty or staff sponsors; the character of any group depends on the particular persons, concerns, and events shaping its work at a given time.

The Trinity faculty has a stable core. Most professors hold tenured or tenure-track positions, and the university makes an effort to retain committed faculty. Together with tenure, the result is that talented and dedicated people offer introductory or signature courses that link generations of students over the faculty member's professional lifetime. An extensive and detailed common curriculum ensures both that students sample a broad range of disciplines, and that they regularly encounter peers with different talents and interests in their classrooms. These encounters reinforce the diversity in living situations that fosters friendships across multiple lines. Every summer, the incoming freshman class reads a book chosen by a faculty committee. It highlights a central theme discussed at one or more events at the beginning of the academic year. Often the author of the book is invited to campus to provide a lecture for the community and a topic of common conversation campus-wide. Professors help students organize class-related on-campus events and sometimes host students at their homes. The integration of faculty and students contributes to the cohesion of the university community and the sense of identity that it generates.

The space and places that constitute "Trinity" in the minds of students, faculty, and administration are so distinctive that its denizens refer to it as the "Trinity bubble". The bubble also comes in for criticism: it insulates students from the problems of urban San Antonio; it doesn't prepare students for the hardships they are likely to encounter in the new economy; and it sometimes takes the "in loco parentis" quality of university life too far. Yet it is appreciated as the signifier of a corporate identity with a proud history and a place in the larger world of the city, the state and, increasingly, of Washington. Faculty members encourage community and sub-community formation and call upon former students to help new graduates get introductions, internships, and jobs. Trinity spaces extend to an ambitious and successful study-abroad program. Rather than limiting possible destinations by establishing overseas centers, Trinity sends its students across the world to a wide range of spaces and places. Perhaps the greatest limitation on where Trinity students can study abroad comes from family members who themselves have not traveled and are apprehensive about their students' safety. When students return, they participate in classes and events that build on their study-abroad experiences, such as photography competitions and seminars.

\subsection{Space and Place at ODU}

ODU, a university that confers a number of graduate as well as undergraduate degrees, occupies a number of spaces between AUK and Trinity as an undergraduate institution. Like AUK, ODU is located near the sea. 
Home of the US Atlantic Fleet, Norfolk has a long history as a major Atlantic port. A remnant of that history intersects with the university. Quarantine Road, part of which remains as a barely visible stone path behind the student center, was the location of the first Quarantine House in Virginia. It was established in the mid-eighteenth century so that ill persons carried by ship to the port could be isolated and cared for in a contained area to prevent contagion. Unlike AUK, where the previous identity of its space is well-known if rarely celebrated, or Trinity, where the terrain of its current space (it has occupied three locations since it was founded in 1869) is integral to campus ceremonies and events, few ODU students are even aware of Quarantine Road. That the university overlooks the largest coal port in the eastern United States is also uncelebrated, but its coastal location is one of its prime attractions and supports excellent programs in oceanography.

ODU's collective identity is organized around athletics. As with other large state universities, ODU athletic events bring faculty, students, and members of the larger community together to root for prize-winning men's and women's basketball teams and, more recently, a new football team. But the foundation of identity for most ODU students lies in programs, departments, and classes taken in their majors.

Unlike AUK and most courses at Trinity, introductory classes at ODU tend to be large, with the main interaction between students and instructors mediated by teaching assistants. Course distribution requirements rarely provide the same quality of common experiences for students that such courses do at AUK and Trinity, both because they rarely involve common enterprises such as group projects, trips, or university events, and because they often are "placeless" even if they are held in the same space. At ODU, majors and professional programs linked to departments and professors form the basis of the collective experiences of graduates. The bonds in these groups can be very strong whether graduates remain in the vicinity or relocate elsewhere. Yet while the ethnic, religious, class, nationality, and other dimensions of diversity of the ODU student body are far broader than at AUK or Trinity, the intellectual experiences and friendships of ODU students tend to be narrower, centered on majors or, as at AUK, upon networks initiated and sustained in the surrounding community rather than in the university as such. For example, in a course on women and the military, students bonded more closely with one another if they shared a military or a civilian identity rather than a common major or even a shared identity as women or men. Distance learning and the number of part-time and returning students also take away from the common experience of some ODU students although others manage to sustain university-initiated and nourished friendships that transcend the communities of origin of their members.

Limits to socialization and informal learning at ODU arise less from spatial or place constraints than because so many students do not spend much time in the university spaces or places that do exist. Students with full-time jobs, returning students with families, students in military families that are themselves transient come for classes and to use the library and laboratories, but spend most of their lives elsewhere. In addition to the family-andfriends demands that AUK students juggle, many ODU students have one or more identities that take priority over their identities as students. They have little time to spend on informal learning with peers and little time to be instructors of their peers. This is one reason why the classroom is such an important space with regard to acquiring friends, networks and resilience, and also why its influence is limited. The adult students already have experienced the rites of passage traditional undergraduates undergo at college. Even from the perspective of the university, most such graduates are not "products" of a unique environment provided by the institution. ODU also sponsors study-abroad programs, but they are less salient and celebrated on the campus than the trips abroad taken by AUK students or the study-abroad program at Trinity. Like other aspects of ODU, they occupy relatively small places in the university space.

\section{Space, Place, and Learning in Foreign Settings: Study Abroad}

Preparing students for professional lives in a globalized world is one reason for encouraging them to study abroad. Businesses and several sectors of public service value the language skills students can acquire abroad and also the demonstration of their ability to adjust to environments and situations that are unfamiliar that an extensive period abroad implies. Employers seek job candidates who can "hit the ground running". To them, study-abroad experience demonstrates both a willingness to venture into alien climes and evidence that the candidate has been able to function successfully there, especially if internships or other experiential learning is part of the package (Redden, 2010; Trooboff et al., 2007-2008).

Study abroad models vary but most range between two ideal types. One houses students from the same university together in the host country. Some classes are taught in the residence house by local faculty and others 
are taken at different institutions across the city. The "purest" version of such "island programs" brings homecountry faculty to the host country to offer courses specifically designed for that group of students. To island programs, the foreign location is a space, but the place of formal education remains the home institution (Norris \& Dwyer, 2005). Students visit local historical sites and museums and avail themselves of other cultural opportunities, but their formal education takes place in a bubble where the main concern is that their classes satisfy graduation requirements at their home institution.

The other end of the continuum is direct enrollment, also called full-immersion programs. Students apply for admission directly to the host institution and take courses there, living among local students, and relying on the foreign university's support services. Trinity's study abroad program is mostly direct enrollment, which offers students the entire world (of academically approved programs in countries the US State Department certifies as safe), some including internships, to choose from. Trinity also offers a handful of island programs, shorter trips under faculty supervision that are similar to the study-abroad trips at AUK. Under direct enrollment, it is rare for more than one student to attend the same institution in the same semester or year. Most study abroad programs such as those at Mines and Central are hybrids that occupy different places on the continuum between these two ideal types.

\subsection{Study Abroad at and from the Colorado School of Mines}

Study abroad at Mines works in both directions, with students from Mines studying abroad and foreign students studying at Mines. Among the goals of the Mines study abroad program is for students to see how things are done abroad, to make contacts with peers and professionals in countries where they might later work, and to be able to hold internships in the industries they are preparing to enter as professionals after graduation (GodelGengenbach, 2013). But like other universities, Mines encourages study abroad for a range of reasons. Students who are highly focused on technical subjects, and/or come from the western United States with little or no experience in foreign countries or even in other regions of the United States, find that study abroad literally opens new worlds. In at least one case, it provided an opportunity for a student who struggled academically. He had limped through his first three years with mediocre grades, and was advised to take his last year abroad. He chose to study in Spain. There he was able to capitalize on his foundation in Spanish, fitting smoothly into his new environment, earning respect for his rapidly improving language skills, and discovering pools of additional expertise he could share with his peers. Now he runs a construction company in the United States, keeps in touch with friends he made in Spain, and is an enthusiastic booster of study abroad.

Foreign students come to Mines for varying periods of time and have to be competent in English before they matriculate. Even so, some find themselves at an academic disadvantage with respect to their American peers. "Americans know the system; they understand that homework and attending class are important. Foreign students need to learn how to participate in those activities" (Godel-Gengenbach, 2013). Examinations are conducted differently and some students do not know how to prepare for them. Students who were successful during their first two or three years at university at home don't always know how to access tutorials that bring students together with a more senior teaching assistant. "Degree-seeking students from their own countries are often too busy to provide adequate assistance, and the ones who need help don't like to ask” (Godel-Gengenbach, 2013).

Foreign students find places to make friends in club sports, a major preoccupation at Mines where talented foreign athletes are sought after and recruited by their American classmates. Foreign students also meet peers at the mosque, in each country's student organization, and in Phi Beta Delta, an international honor society. Students from the Gulf usually have to get used to coeducation which, inasmuch it exists at all at home, could in practice mean that male and female students are separated by a wall down the center of the classroom. Despite a popular on-going design program with Abu Dhabi, it took five years for Emerati women to be sent to Mines. On the other hand, Saudi women have studied at Mines for some time. They tend to do as well academically as their male compatriots and many find employment with the national oil company, Saudi Aramco, after graduation.

Mines hopes to increase the proportion of US students studying abroad, now about 27 percent of undergraduates. It has links with universities around the world, including in the Gulf. The Petroleum Institute (PI) in Abu Dhabi began as a joint venture with the UAE and Mines. Now, under the direction of the Emeratis, the PI has become an exchange program destination for Mines students and interns. Among the Emeratis who come to Mines are graduate students and professionals enrolled in continuing education programs. In 2012 three Mines 
students participated in the exchange program at the PI. As the first exchange students at the PI, they learned about the region, took courses consistent with their degree plans, and one even obtained a summer internship with ADNOC, the national oil company. Yet one American student was turned down by the PI because he came from an Afghan background, even though he was a US citizen. Some Mines students spend a semester at Montanuniversitat Leoben (one of Mines’s first partners), and others study foreign languages in France, Spain, and Germany.

\subsection{Study Abroad at Central}

Study abroad at and from Mines is directed toward professional preparation. It reflects the university’s mission, and incorporates aspects of direct enrollment and modified versions of island programs at selected foreign institutions such as the PI. At Central College in Pella, Iowa, the study abroad program, started in 1965, is designed to enlarge the life experiences of a small population of students, most of whom come from Iowa or nearby states, by giving them the chance to study and live abroad. About half of Central students study abroad for a semester or more at one of six locations in Europe and one in Latin America. Central's program is a hybrid that comes closer to the island end of the spectrum. Students study and take some classes together and also take courses at a local university. Some US students come from other US schools, and the program centers make an effort to incorporate foreign students from the local area in their activities. A few students study in other programs that more closely resemble direct enrollment. In 2013, two were in Oman and one was in China (Zylstra, 2013).

"The study abroad experience for most is the first time they have been far away from home for a significant amount of time." The "leaving home” experience is a primary element in the intense bonding that students undergo when they are abroad. "I am mid-career now but we are still connected. When we run into one another it's 'do you remember?’” (Zylstra, 2013). Among the goals of Central’s program is to give students the opportunity to improve their skills in the local language; to learn about the local culture; to experience personal development- “study abroad is a perfect environment for personal growth... encouraging students to become adaptable, to 'work in the grey”' (Zylstra, 2013).

Professional experience is not a focus of Central's program although it does influence the careers of some students. "For education majors, it affects how they behave as teachers. They have a global perspective. [Program alumni] see it as changing their approach.” Central business majors choose to study abroad "because of the internship programs, and because they understand that business is international, and realize the importance of having international experience" (Zylstra, 2013). Although the explicit aims of study abroad differ between these two institutions, it is clear that the experiences of students in both programs are similar. Study abroad as such offers unique places for indirect learning in spaces all over the world.

\section{3. "US Most Preferred Destination for Saudi Students"}

The King 'Abdullah scholarship program (KASP) offers two different pools of Saudi youth the opportunity to study in a wide range of degree programs abroad. The scholarship pays tuition and travel, medical expenses, and a monthly salary to a small number of elite applicants residing in Saudi Arabia, and any Saudi nationals currently living abroad (Handbook for Saudi Scholarship Students, 2009, cited in Hausheer \& Toops, 2012). Consequently, this program is both a small, highly selective scholarship opportunity available only to a small pool of elite applicants in Saudi Arabia and an all-welcoming program to Saudi nationals already residing in the United States (Hausheer \& Toops, 2012). Of the nearly 150,000 students world-wide receiving KASP grants, more than 69,000 are currently studying in the United States (US Most Preferred, 2013).

Study abroad is one of the ways that Saudi Arabia copes with the upsurge of demand for higher education that characterizes most Gulf Cooperation Council (GCC) states. Unlike Kuwait, Saudi Arabia also is investing in expanding colleges and universities at home (D’Andrea, 2009; Davidson \& Smith, ed., 2008; Hausheer \& Toops, 2012). Officially, the purpose of KASP resembles the goals of US-based study-abroad programs: to foster cultural exchange and to provide students with a broad range of opportunities to advance their educations. Other purposes deduced in a recent study of the KASP program in the United States include strengthening the patronage networks that shore up the regime, diffusing potential unrest among Saudi youth, and demonstrating a commitment to reforming education for women who make up more than 23 percent of KASP students (Hausheer \& Toops, 2012; US Most Preferred, 2013).

The importance of training students for future employment explains why the Saudi government promotes 
study in the so-called STEM fields: science, technology, engineering, and mathematics. It hopes that students will return to work in government and private-sector positions which operate under "Saudization" mandates requiring the gradual replacement of foreign with domestic employees. During the first round of the KASP program in the United States, the Saudi Arabian Cultural Mission (SACM) selected both the school and the major for each recipient. Now, according to one student in the program, "nearly any major is permitted by SACM even those not on the 'approved' list”" (Hausheer \& Toops, 2012: 39), which include in addition to STEM fields, medicine, accounting, law, and those preparing graduates for work in the tourism industry. An education analyst interviewed by Stefanie Hausheer and Gwendolyn Toops (2012: 39-40) said that the growing leniency was a response to the students' preference for study in the United States, both for practical reasons (cost of living) and because that is where they want to live. They appreciate their new-found independence, the freedom they enjoy, and the chance to go to concerts, films, and other public events. They like meeting different kinds of people ("mixing with all races... [learning] respect for other opinions... and other religions" [Hausheer \& Toops, 2012: 60]) and the women like being out from under the Saudi law that forbids them to drive (Wagner, 2011).

Majors are spreading into different fields, however, and the vastly different backgrounds from which students are drawn also contribute to rising heterogeneity in the program. Most of the KASP students studying in the United States do not come through the highly competitive national selection process. They are self-selectedi.e., they must fulfill the same citizenship, age, and employment criteria and, if they are women, live with a male guardian during their time abroad—but otherwise they can simply apply for a scholarship if they are accepted in an English as a Second Language (ESL) program and travel to that US institution and request support from SACM (Hausheer \& Toops, 2012: 36-38). Although most believe that a US degree is better than a Saudi degree in the same field (Hausheer \& Toops, 2012: 56), many realize that it is likely to be difficult to get jobs when they return home, especially women to whom most jobs are closed, while family and legal constraints make working outside the home logistically and social daunting (Hausheer \& Toops, 2012: 56-58; Wagner, 2011).

Most observers see KASP as expanding the world views, networks, and resilience of students but also note that their experiences are limited by the objectives of their government and society (e.g. Hausheer \& Toops, 2012; Wagner, 2011). This makes much of the study abroad experience one of space rather than place. Studyabroad students from any country may isolate themselves by spending more time with peers from their home countries and regions than they do with locals, or by immersing themselves in social media rather than building social relationships in the host country (Huesca, 2013). Just as limiting are the attitudes and shortcomings of the receiving institutions and communities.

Anecdotal evidence and conversations with Saudis participating in the [KASP] program indicate that Saudi students are often ghettoized during their time in the United States. It is easier for them to live with and befriend people who speak Arabic, and to form friendships with other Saudis. Many live with siblings, making it even more difficult for them to immerse themselves fully in American culture. Recent conversations confirm that many Saudis want to socialize with Americans but are shy or do not know how to engage with them. Women face particular challenges in this regard... [T] he sensible response would be to... develop initiatives and programs to more effectively connect these Saudi students to Americans. This would involve not only university communities, but local service organizations, schools, nongovernmental organizations, and businesses. Perhaps one component of these initiatives should be connecting Saudi students to American host families. Living with a host family would encourage Saudis to practice their English while at the same time immersing them in American culture. Ideally, this experience would forge lasting friendships and enhance cultural awareness between Saudi students and their host family. Such exchanges, though not without challenges, would also help alleviate American misconceptions about Saudi Arabia (Lebaron \& Hausheer, 2013).

This assessment reflects an appreciation of the benefits of study-abroad outcomes desired by sending countries for the receiving society as well. Greater integration of study-abroad students in host-country communities can generate places for participants within and beyond the spaces of nations. Programs that feature home stays, like many Trinity study-abroad locations, embody the precise conditions outlined above.

\section{Conclusions}

Cities are imagined as cosmopolitan spaces in which novelty, diversity, and congenial places for human interac- 
tion enrich the lives of their inhabitants. Universities share some of these qualities whether they are located in urban environments or not. Often they are the first such cosmopolitan spaces encountered by undergraduates. The university space allows students gradually to distinguish between the concrete notion of space as location and metaphorical, more complex, notions of space and place as networks and communities where human action takes place (Arendt, 1959). The development of Arendtian "spaces of appearance” is limited by the extent of students' encounters with difference, and how little or much they can or must adjust to it. The three universities discussed in this essay represent different understandings of space and place. All three feature programs that enlarge the space and the number of places of formal and informal learning where students can begin to develop social and professional networks and thereby the autonomy and resilience that underpin adult success. Some of these programs are campus-based but others include ventures as close as internships in a local industry and as distant as study abroad on another continent.

Each setting supports a different relationship between student and university. AUK and ODU are not exclusive life spaces as Trinity is for its students during their first three years. Whether enclosed, such as the AUK campus, or spread across a wide geographic area, like ODU, these two institutions are places to learn and make friends for students whose lives are rooted in the homes, families-and-friends, and jobs outside where they spend at least as much of their time. They have opportunities to bond to fellow students but the university community is rarely the primary source of identity for such student inhabitants. In contrast, Trinity takes the place of home and family at the center of student identity to the extent that its denizens see their community as a bubble from which they experience everything else as outside. Dormitory living, small classes, shared experiences, and the conscious development of common values and goals encourage bonding among a diverse collection of students and faculty that lead to life-long relationships centered on the Trinity experience. To let in more people and a wider range of experiences, Trinity, like Mines and Central, also emphasizes experiential and informal learning off-campus, in study-abroad programs, internships, and community outreach. Such programs extend the spaces of these universities and incorporate the places they occur into the student experience. Even so, Trinity prefers that such experiences not interfere with the bond between the student and Trinity. Unlike Mines, Trinity discourages study abroad during a student's senior year (Ericksen, 2013). The study-abroad program at Central also regards student-college bonding as a priority of its modified island program.

Among the goals of creating off-campus spaces and places of learning is to enable students to acquire measurable skills, like language proficiency and job experience, that add to their desirability as new hires after graduation. In addition, students are assumed to have acquired the capacity to adjust to new situations and thrive in novel environments, characteristics that give their holders an advantage in a globalizing world. Yet the mere fact of studying abroad or holding an internship is not a guarantee of these capacities. Even the ESL programs taken by Saudi exchange students do not guarantee the same level and ease in conversation and reading that an extended home stay is likely to provide. Similarly, although trips abroad enrich the education of AUK students, they do not provide the same experience as "leaving home" and having to manage in another world. While every study-abroad program brings benefits to students, those that not simply enable but actually require participants to engage locally - to break the bubble of the home identity in order to learn to operate successfully in the host country-are the ones that deliver the most benefit to the individual and the employer. In sum, indirect learning is as important as programs and courses in preparing students for adult life. Like the formal attributes of these spaces of education, the informal places also should be investigated before students make choices likely to determine the trajectory of the rest of their lives.

\section{Acknowledgements}

An earlier version of this paper was presented at the Conference on Gulf Cities held at the American University of Kuwait, Kuwait City, March 2013. I would like to thank the participants, particularly Chris Ohan, whose helpful comments guided the revisions for which I alone am responsible.

\section{References}

Arendt, H. (1959). The Human Condition. Garden City, NY: Anchor Books.

BBC (2012). The Age of Reason: Professor Romila Thapar. First Broadcast 8 December. http://www.bbc.co.uk/programmes/p011cfvy

D’Andrea, V. (Ed.) (2009). Special Issue: Quality Developments in the Gulf. Quality in Higher Education, 15. 
http://www.tandfonline.com/loi/cqhe20\#.VK_rPSvF-TJ

Davidson, C., \& Smith, P. (Eds.) (2008). Higher Education in the Gulf States: Shaping Economics, Politics and Culture. London: Saqi Books.

Ericksen, N. (2013). Telephone Interview. 19 February.

Fischer, K. (2013). The Employment Mismatch: A College Degree Sorts Job Applicants, But Employers Wish It Meant More. Chronicle of Higher Education. http://chronicle.com/article/The-Employment-Mismatch/137625/

Frost, R. (1914). Death of the Hired Man. http://www.poetryfoundation.org/poem/173525

Godel-Gengenbach, K. (2013). Interview. 27 February. Golden, CO.

Hamzeh, N. (2010). Interview. 3 May. Kuwait City, Kuwait.

Hausheer, S., \& Toops, G. (2012). 67,000 Saudis in America: The King ‘Abdullah Scholarship Program’s Potential Impact on Saudi society. George Washington University IMES Capstone Paper Series.

Holt-Jensen, A. (1999). Geography, History and Concepts. London: Sage Publications.

Huesca, R. (2013). How Facebook Can Ruin Study Abroad. Chronicle of Higher Education. http://chronicle.com/article/How-Facebook-Can-Ruin-Study/136633/

Hrdy, S. (2011). Mothers and Others: The Evolutionary Origins of Mutual Understanding. Cambridge, MA: Belknap Press.

IES (n.d.). Study Abroad: A Lifetime of Benefits. IES Abroad News. http://www.iesabroad.org/study-abroad/news/study-abroad-lifetime-benefits

Lebaron, R., \& Hausheer, S. (2013). Americans Must Do More to Welcome Saudi Scholarship Students. US News and World Report. http://www.usnews.com/opinion/blogs/world-report/2013/03/01/americans-must-do-more-to-welcome-saudi-scholarship-s tudents

N. A. (2012a). Imagine Cup: More Than a Competition. AUK Chronicle, 6-9. http://www.auk.edu.kw/administration/uni_publications/chronicle_mag/2012/AUK_Chronicle_NOV2012.pdf

N. A. (2012b). Kuwait at Fifty. AUK Chronicle, 4-5. http://www.auk.edu.kw/administration/uni_publications/chronicle_mag/2012/AUK_Chronicle_NOV2012.pdf

Norris, E. M., \& Dwyer, M. (2005). Testing Assumptions: The Impact of Two Study Abroad Program Models. Frontiers: The Interdisciplinary Journal of Study Abroad, 11, 121-142. http://eric.ed.gov/?id=EJ891466

Pearson, C. (2012). AUK Students Share Knowledge and Creativity at Dartmouth College. AUK Chronicle, 12-13. http://www.auk.edu.kw/administration/uni publications/chronicle mag/2012/AUK Chronicle NOV2012.pdf

Redden, E. (2010). Academic Outcomes of Study Abroad. Inside Higher Ed. http://www.insidehighered.com/news/2010/07/13/abroad

Sotomayor, S. (2013). My Beloved World. New York: Alfred Knopf.

Sulloway, F. (1996). Born to Rebel: Birth Order, Family Dynamics, and Revolutionary Genius. New York: Pantheon.

Tétreault, M. (1993). Civil Society in Kuwait: Protected Spaces and Women’s Rights. Middle East Journal, 47, $275-291$. http://www.jstor.org/stable/4328572

Tétreault, M. (2011). Identity and Transplant-University Education in the Gulf: The American University of Kuwait. Journal of Arabian Studies, 1, 79-95. http://www.tandfonline.com/doi/abs/10.1080/21534764.2011.576052

Trooboff, S., Vande Berg, M., \& Rayman, J. (2007-2008). Employer Attitudes toward Study Abroad. Frontiers, 15, 17-33. http://www.frontiersjournal.com/frontiersjournal.comissuesvol15index.htm http://eric.ed.gov/?id=EJ878375

US Most Preferred Destination for Saudi Students: Ministry. Arab News, 7 March 2013. http://www.arabnews.com/saudi-arabia/us-most-preferred-destination-saudi-students-ministry

Wagner, R. (2011). News Analysis: The Saudi Arabian Female Brain Drain. Mid East Posts—The Voices of the Middle East. https://sites.google.com/site/roblwagnerarchives/the-saudi-arabian-female-brain-drain

Zylstra, B. (2013). Telephone Interview. 21 February. 
Scientific Research Publishing (SCIRP) is one of the largest Open Access journal publishers. It is currently publishing more than 200 open access, online, peer-reviewed journals covering a wide range of academic disciplines. SCIRP serves the worldwide academic communities and contributes to the progress and application of science with its publication.

Other selected journals from SCIRP are listed as below. Submit your manuscript to us via either submit@scirp.org or Online Submission Portal.
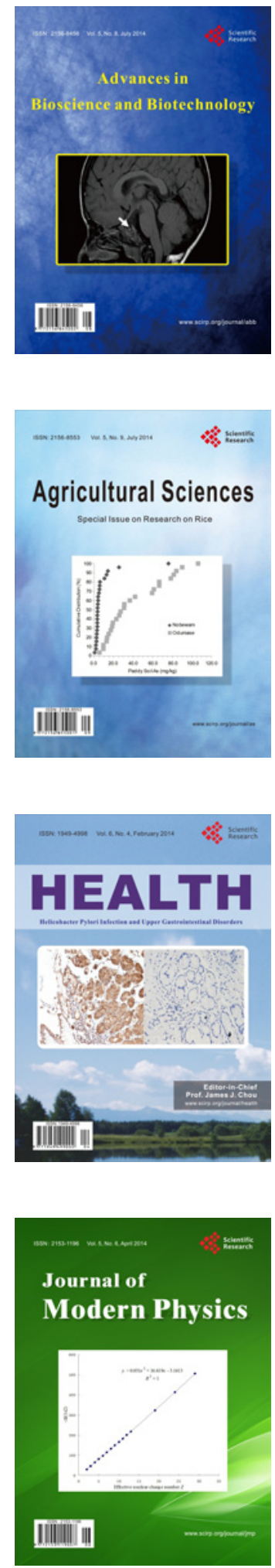
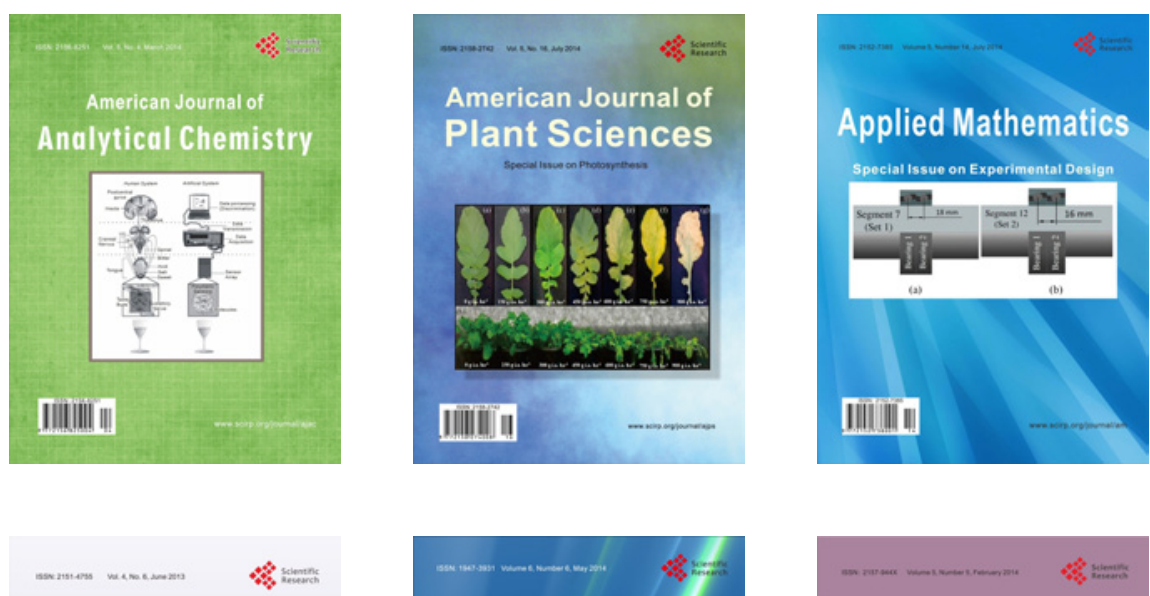

Creative Education
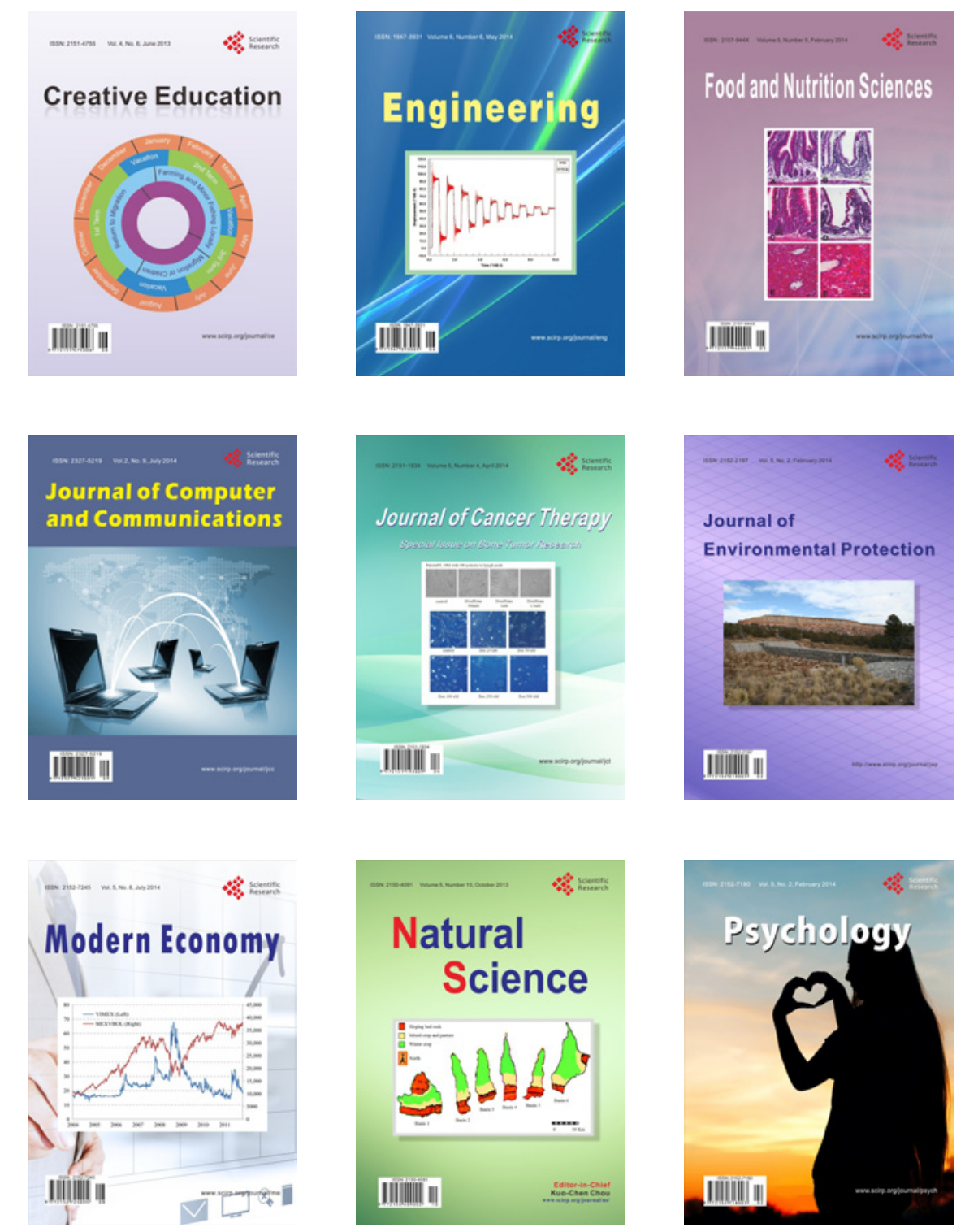